\title{
Leptin receptor deficiency: a systematic literature review and prevalence estimation based on population genetics
}

\author{
Lotte Kleinendorst ${ }^{1,2,3, *}$, Ozair Abawi3,4,*, Hetty J van der Kamp5 ${ }^{5}$, Mariëlle Alders², Hanne EJ Meijers-Heijboer ${ }^{1,2}$, \\ Elisabeth F C van Rossum ${ }^{3,6}$, Erica L T van den Akker ${ }^{3,4}$ and Mieke M van Haelst ${ }^{1,2}$
}

${ }^{1}$ Department of Clinical Genetics, Amsterdam UMC, University of Amsterdam, Amsterdam, The Netherlands, ${ }^{2}$ Department of Clinical Genetics, Amsterdam UMC, Vrije Universiteit Amsterdam, Amsterdam, The Netherlands, ${ }^{3}$ Obesity Center CGG, Erasmus MC, University Medical Center Rotterdam, Rotterdam, The Netherlands, ${ }^{4}$ Department of Pediatrics, Division of Endocrinology, Erasmus MC-Sophia Children's Hospital, University Medical Center Rotterdam, Rotterdam, The Netherlands, ${ }^{5}$ Department of Pediatrics, Division of Endocrinology, Wilhelmina Children's Hospital, University Medical Center Utrecht, Utrecht, The Netherlands, and ${ }^{6}$ Department of Internal Medicine, Division of Endocrinology, Erasmus MC, University Medical Center Rotterdam, Rotterdam, The Netherlands

*(L Kleinendorst and O Abawi contributed equally to this work)

\section{Correspondence} should be addressed to $E L T$ van den Akker or $M$ M van Haelst Email

e.l.t.vandenakker@ erasmusmc.nl or $\mathrm{m}$. vanhaelst@amsterdamumc.nl

\begin{abstract}
Objective: Leptin receptor (LepR) deficiency is an autosomal-recessive endocrine disorder causing early-onset severe obesity, hyperphagia and pituitary hormone deficiencies. As effective pharmacological treatment has recently been developed, diagnosing LepR deficiency is urgent. However, recognition is challenging and prevalence is unknown. We aim to elucidate the clinical spectrum and to estimate the prevalence of LepR deficiency in Europe.

Design: Comprehensive epidemiologic analysis and systematic literature review.

Methods: We curated a list of LEPR variants described in patients and elaborately evaluated their phenotypes. Subsequently, we extracted allele frequencies from the Genome Aggregation Database (gnomAD), consisting of sequencing data of 77165 European individuals. We then calculated the number of individuals with biallelic disease-causing LEPR variants. Results: Worldwide, 86 patients with LepR deficiency are published. We add two new patients, bringing the total of published patients to 88, of which 21 are European. All patients had early-onset obesity; $96 \%$ had hyperphagia; $34 \%$ had one or more pituitary hormone deficiencies. Our calculation results in 998 predicted patients in Europe, corresponding to a prevalence of 1.34 per 1 million people $(95 \% \mathrm{Cl}: 0.95-1.72)$.

Conclusions: This study shows that LepR deficiency is more prevalent in Europe ( $n=998$ predicted patients) than currently known ( $n=21$ patients), suggesting that LepR deficiency is underdiagnosed. An important cause for this could be lack of access to genetic testing. Another possible explanation is insufficient recognition, as only one-third of patients has pituitary hormone deficiencies. With novel highly effective treatment emerging, diagnosing LepR deficiency is more important than ever.
\end{abstract}

European Journal of

Endocrinology

(2019) 182, 47-56

\section{Introduction}

Obesity is one of the most urgent health problems of modern times because of its epidemical prevalence, high disease burden, and high mortality (1). In rare cases, obesity (c) 2019 European Society of Endocrinology Printed in Great Britain is caused by genetic disorders in the leptin-melanocortin pathway, the hypothalamic system controlling energy expenditure and food intake. The anorexic hormone leptin is mainly secreted by adipose tissue and reflects the body's energy reserves. Hypothalamic leptin signaling

Published by Bioscientifica Ltd. 
leads to activation of the melanocortin-4-receptor (MC4R), resulting in increased energy expenditure and satiety. When this signaling is disturbed, patients develop hyperphagia and early-onset obesity. A recent breakthrough for leptin-melanocortin pathway disorders is treatment with MC4R-agonist setmelanotide, which results in impressive weight loss (2). One of the endocrine disorders that now can be treated is leptin receptor (LepR) deficiency, a rare autosomal recessive disorder caused by pathogenic variants in the leptin receptor gene (LEPR). Adequate functioning of the leptin receptor is essential for maintaining body weight. Moreover, adequate leptin signaling is necessary for onset of puberty, pubertal growth spurt, and production of thyroid-releasing hormone $(3,4)$. Additionally, LepR-deficient rodents show decreased levels of pituitary growth hormone and stunted growth curves (5). When looking at the phenotype of LepR deficiency in humans, patients with LepR deficiency indeed can exhibit hypogonadotropic hypogonadism $(\mathrm{HH})$, hypothyroidism, and/or growth hormone deficiency (GHD) in addition to extreme early-onset obesity and hyperphagia. It remains unclear why some patients only exhibit severe obesity, whereas others also have the associated pituitary hormonal disturbances. Residual receptor activity associated with specific LEPR mutations might partially explain this (4), but has not been investigated systematically. Other features reported in patients with LepR deficiency are frequent infections and hyperinsulinemia $(3,4)$, but to what extent they are part of the clinical spectrum of LepR deficiency is unknown. In some patients a lower CD4+ T-cell count and a compensatory higher B-cell count has been reported, which is in accordance with known effects of leptin on the immune system (4). It is hypothesized that this may contribute to early childhood death due to infections (4). Individuals affected by LepR deficiency have hyperinsulinemia to a degree consistent with the severity of their obesity (4), although it is suggested that these patients might be predisposed to develop insulin resistance and diabetes at an earlier age (3). The phenotype variability makes identification of LepR deficiency challenging. Recognition might be further hampered due to lack of awareness of possible rare underlying causes in routine obesity care. In obesity cohort studies, LepR deficiency prevalence of $0-3 \%$ is found $(4,6,7,8)$. Higher prevalence of up to $10 \%$ is reported in cohorts from consanguineous families (9). However, it is important to realize that these estimations only reflect prevalence of LepR deficiency in selected patient groups. The traditional approach to prevalence estimations of genetic diseases (counting the people diagnosed with the disease) greatly depends on local availability and application of genetic testing. Nowadays, genetic data from large population databases can be used to better estimate general prevalence of genetic disorders.

Aim of this study is to establish the prevalence of LepR deficiency in the general European population. To achieve this, we first performed a systematic literature review to identify all published cases and add unpublished cases from our obesity center. We use the LEPR variants from these cases to perform a prevalence estimation based on European allele frequencies. Our second aim is to gather clinical information from published LepR deficiency patients to describe the clinical spectrum.

\section{Methods}

\section{Systematic literature search}

A systematic literature search was performed in Embase, Medline (Ovid), Web of Science, Cochrane Library, and Google Scholar to identify all patients with LepR deficiency from its first report in 1998 up to May 2019. The complete search strategy is presented in the supplement (Supplementary file 1, see section on supplementary materials given at the end of this article). In short, the strategy consisted of the themes 'LEPR'/'LepR deficiency' or 'obesity genetic diagnostics'. We adopted a broad search strategy to not miss studies which sequenced $L E P R$ as part of an obesity gene panel. Additionally, we searched for additional cases in ClinVar, the Human Gene Mutation Database, and the Decipher database $(10,11,12)$. Finally, we performed a non-systematic search in Researchgate (www.researchgate.net; accessed 24-05-2019; search queries 'LEPR', 'leptin receptor' and 'leptin receptor deficiency') to identify studies and conference abstracts that were not indexed in the mentioned databases.

Title and abstract of all identified studies were screened by two investigators (L K, O A); studies describing patients with LepR deficiency were included; duplicate studies were removed (Fig. 1). In case of disagreement over inclusion, a senior investigator ( $\mathrm{E} v \mathrm{~d} \mathrm{~A} / \mathrm{M} \mathrm{v} \mathrm{H}$ ) served as adjudicator. Additionally, reference lists of included studies were screened for relevant articles. Follow-up studies on cases already described in literature were only used for phenotype assessment.

\section{Data extraction from included articles}

An overview of genetic aberrations and phenotype features of patients with LepR deficiency (early-onset obesity, hyperphagia, signs of hypopituitarism and 


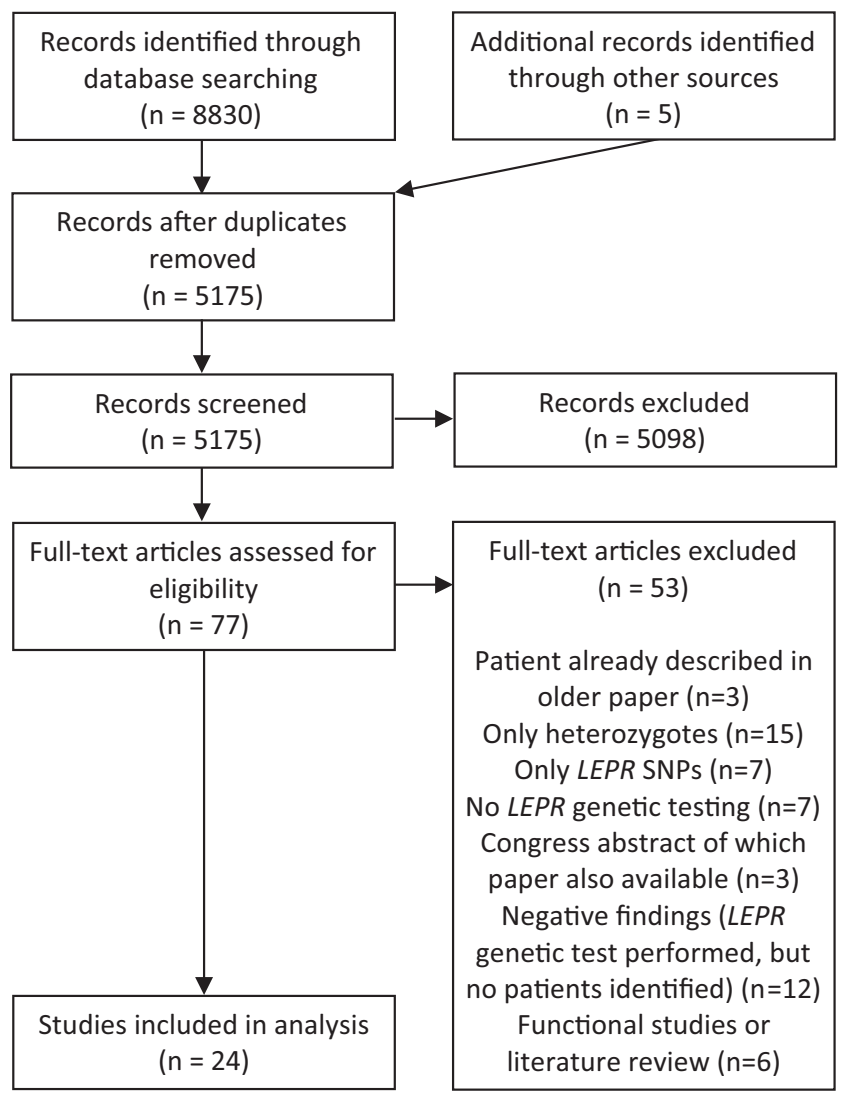

\section{Figure 1}

PRISMA flow diagram of systematic literature search. LEPR, leptin receptor gene, SNP, single nucleotide polymorphism.

frequent infections) was made. When standard deviation scores (SDS) were not originally reported for anthropometric data, we calculated these using WHO growth charts as external standard (13). In case insufficient clinical data were reported, we tried to contact corresponding authors to provide additional information.

\section{Case presentation of Dutch patients with LepR deficiency}

We present two novel cases of LepR deficiency identified in our obesity center. Written informed consent for publication of their clinical details was obtained from the patient and/or parents. For these two patients' anthropometric data, SDS are presented using Dutch growth charts as external standard (14).

\section{Selection of variants in LEPR}

We extracted disease-associated LEPR variants from published cases identified through our systematic literature search and added in-house genetic data (Table 2). Additionally, we curated and added variants with a high likelihood of being pathogenic, that is, loss-of-function (LoF) variants that were proximal to the pathogenic variant p.S1090Wfs*6. This variant is the most distal pathogenic variant reported in a patient with LepR deficiency; hence, LoF variants located more proximally are very likely to cause LepR deficiency. For all selected LEPR variants, we extracted allele frequencies from the Genome Aggregation Database (gnomAD). The gnomAD database (https://gnomad.broadinstitute.org/; accessed 06-10-2019) is the largest freely accessible populationbased database consisting of sequencing data from 77 165 Europeans. Individuals with known severe pediatric diseases and their first-degree relatives are removed from this database. We excluded variants that did not pass gnomAD's quality control. Because of their distinctive genetic background, Finnish individuals are often omitted from European population studies. However, by performing separate prevalence calculations for Finnish and Non-Finnish cases, we could aggregate the results and provide estimations for the whole European population. All selected $L E P R$ variants were evaluated by a clinical laboratory geneticist according to the current international guideline for variant classification (15). All variants are aligned to the canonical transcript NM_002303.5.

\section{Prevalence calculation}

We extracted European population size from the 2019 United Nations World Population Prospects report, which estimates a population size of 747.183 million Europeans, of which 5.532 Finnish Europeans (https://population.un.org/wpp/Download/Standard/ Population/; accessed 28-09-2019). We estimated the number of individuals with biallelic (homozygous or compound heterozygous) pathogenic LEPR variants by calculating the probability of homozygosity or compound heterozygosity for each possible combination of our selected variants. We assumed that the population was in Hardy-Weinberg equilibrium and that random mating between individuals with and without obesity occurred. We did not correct for specific genetically isolated consanguineous populations in Europe. The CI of our prevalence estimation was calculated using derived variances (16). We adapted the formulas to allow derivation based on the sum of independent random variables. 


\section{Results}

\section{Systematic literature search and overview of published cases}

In total, 5175 records were screened (Fig. 1), of which 24 records presented unique patients with LepR deficiency and were eligible for inclusion $(2,4,5,7,9,17,18,19,20$, $21,22,23,24,25,26,27,28,29,30,31,32,33,34,35$ ). From these 24 records, we identified $n=86$ unique patients with LepR deficiency from 57 different families. We add two new unrelated cases with LepR deficiency (Box 1). Including these two new cases, 88 patients have now been described worldwide (Table 1), harboring 45 distinct LEPR variants (Table 2). Twenty-one of these patients are from European ancestry. To gain more insight in the clinical spectrum of the disease, the phenotypes are summarized in Table 1 and presented on individual level in Supplementary Table 1. Consanguinity was reported in $65 / 88$ (74\%) patients. Of the 84 patients in which sex was reported, $42(50 \%)$ were female. Median age at description was 8.0 years (IQR: $3.0-15.2$ years). Eighteen $(22 \%)$ out of the 83 patients in which age was reported were adults, the three oldest of which were 39,41 , and 55 years old. Median BMI was $39.6 \mathrm{~kg} / \mathrm{m}^{2}$ (IQR: $34.1-$ $49.1 \mathrm{~kg} / \mathrm{m}^{2}$ ). Mean BMI SDS was +5.2 (SD 2.0) and was not significantly different between males and females
$(P=0.39)$. Interestingly, three patients (Dehghani III:9 and III:10, Kakar VII:6) did not have obesity at presentation. A large inter-individual variation was seen with respect to height SDS (mean +0.3 SDS, s.D. 2.1; reported in 49/88 patients): $11 / 49$ (22\%) patients had a tall stature (height SDS $>2)$, whereas $8 / 49(16 \%)$ patients had a short stature (height SDS <-2). Early-onset obesity (<age 5 years) and hyperphagia were the most common phenotypic features (Table 1). In 21 cases, exact age of onset of obesity was reported; when aggregated, median age of onset was 0.3 years (IQR 0.2-0.4). Pituitary hormone disturbances were present in 24 patients (Table 1 ). In the majority of these patients $(15 / 24,63 \%)$, only one pituitary hormone disturbance was present. Three patients had both $\mathrm{HH}$ and GHD; one patient had HH and central hypothyroidism; one patient had GHD and central hypothyroidism. Three patients had HH, GHD as well as central hypothyroidism.

\section{Known and likely pathogenic LEPR variants}

Of the 45 distinct variants described in patients with LepR deficiency, only eight variants were present in the global gnomAD population, and seven were present in the European population of the gnomAD database (Table 2). Additionally, 20 LoF variants with a high likelihood of being pathogenic were identified in

\section{Box 1: Presentation of two new cases with LepR deficiency}

The first patient is a 3-year-old boy, referred at age 13 months because of increased linear growth, obesity and hyperphagia. He was born at a gestational age of $36+6$ weeks with normal birth weight $(3840 \mathrm{~g},+0.9$ SDS). Parents did not report consanguinity, but their families lived in the same small Dutch municipality. There was no history of frequent infections. On presentation at age 13 months, height was $83.2 \mathrm{~cm}$ (+1.9 SDS), weight $17 \mathrm{~kg}(+4.9 \mathrm{SDS})$, and BMI $24.6 \mathrm{~kg} / \mathrm{m}^{2}$ (+4.4 SDS). Laboratory testing showed a central hypothyroidism. A growth hormone test was performed because of height deceleration, which confirmed GHD. Thyroid and growth hormone supplementation were started. Adrenal insufficiency was excluded by a high-dose ACTH test. MRI cerebrum revealed no anatomic abnormalities in the pituitary region. Obesity gene panel analysis (described in detail elsewhere (6)) revealed a homozygous variant of uncertain significance (VUS) in LEPR: c.3414dup p.(Ala1139Cysfs*16). This variant is located in the C terminal domain of the transcript. Since this is a frameshift near the end of the protein, replacing the last 27 amino acids with 15 alternative amino acids, the clinical relevance remains uncertain. However, the typical clinical phenotype (including hormonal disturbances) in the absence of other plausible explanations, makes this homozygous variant the most probable cause of the LepR deficiency phenotype.

The second patient is a 15-year-old girl referred to our obesity center at age 14 years for personalized treatment advice. She was born at a gestational age of 42 weeks with normal birth weight ( $3400 \mathrm{~g},-0.1 \mathrm{SDS}$ ). At age 3.5 years, she was referred to a pediatric endocrinologist for evaluation of hyperphagia and obesity. There was no history of frequent infections. Height was $97 \mathrm{~cm}(-1.2 \mathrm{SDS})$, weight $23.1 \mathrm{~kg}(+3.0 \mathrm{SDS}), \mathrm{BMI} 24.6 \mathrm{~kg} / \mathrm{m}^{2}$ (+4.4 SDS). Laboratory testing showed no signs of hypopituitarism. During clinical follow-up, she had spontaneous start and progression of puberty and menarche at age 12.5 years. Whole-exome sequencing analysis revealed compound heterozygosity for two known pathogenic variants in the LEPR gene: c.1835G>A (p.Arg612His), c.2051A>C (p.His684Pro). Previously reported functional studies confirmed impaired functionality of the His684Pro variant, whereas the Arg612His variant has some residual function (4). 
the European population of the gnomAD database (Supplementary Table 2). As expected, no (likely) pathogenic variants were present in a homozygous state in gnomAD.

\section{Prevalence calculation}

The calculated number of individuals with LepR deficiency (caused by biallelic disease-causing variants in the LEPR gene) in Europe is 998 patients (95\% CI 708-1288). This would indicate that only 21/998 (2.1\%) European cases with LepR deficiency are currently described in literature. The prevalence of LepR deficiency based on published European patients would be 0.03 per 1 million people. However, our calculated 'genetic prevalence' of LepR deficiency in Europe is 1.34 per 1 million people (95\% CI 0.95-1.72 per 1 million people).

\section{Discussion}

Leptin receptor deficiency is a rare endocrine disease, but our population genetics-based analysis shows that it is much more prevalent in Europe than expected based on literature. Assuming that most patients with LepR deficiency have been published, as is demonstrated by the ongoing reports of new cases in the past years, this suggests underdiagnosis. This is especially problematic since diagnosing LepR deficiency now has therapeutic consequences: pharmacological treatment aimed at restoring the leptin-melanocortin pathway has recently shown impressive results in terms of weight loss, satiety, and improvement of metabolic parameters (2).

Genetic testing for obesity disorders, including LepR deficiency, is recommended in patients with extreme early-onset (before age 5 years) and clinical features of a genetic obesity disorder and/or a positive family history for extreme obesity (36). However, a recent review from the United States reports that only $8 \%$ of patients in whom genetic testing would be indicated had undergone genetic testing (37). An important reason for underdiagnosing might be limited access to genetic diagnostics. Although LEPR sequencing has become available in clinical practice in the last decade, it is not yet part of routine care in many countries. Indeed, all published European LepR deficiency cases

Table 1 Summarized overview of clinical characteristics of all 88 currently known patients with LepR deficiency.

\section{$n$ patients with available data}

Features

Early-onset obesity

(out of 88 )

87

Hyperphagia

Pituitary hormone disturbances

Central hypothyroidism

Growth hormone deficiency*

Hypogonadotropic hypogonadism

39

Hyperinsulinemia

Frequent infections
44

\section{Interpretation}

Present in 87 (100\%) patients:

- 51 (59\%) onset before age 2 years

- $7(8 \%)$ in (early) infancy

- 5 (6\%) onset between age 2-6 years

- $1(1 \%)$ onset before age $13-14$ years

- $23(26 \%)$ not further specified

Present in 81 (96\%) patients

Present in 24 (34\%) patients

Present in $8(13 \%)$ patients

Present in $8(13 \%)$ patients

Additionally:

- $3(6 \%)$ IGF-1 values below reference range reported

- $1(2 \%)$ patients short stature reported

Present in 22 (56\%) patients

Additionally:

- $1(3 \%)$ inconclusive due to young age but low gonadotrophins reported

Present in 24 (39\%) patients

Additionally:

- $10(16 \%)$ inconclusive because no reference range for insulin values was reported

Present in 23 (52\%) patients, of which 3 died due to infections in childhood

Additionally:

- 2 (5\%) lowered CD4+ T cell count reported

- $1(2 \%)$ alterations in immune function reported

*Formal diagnosis of growth hormone deficiency by appropriate $\mathrm{GH}$ provocation tests. CD4, cluster of differentiation 4; IGF-1, insulin-like growth factor 1. 

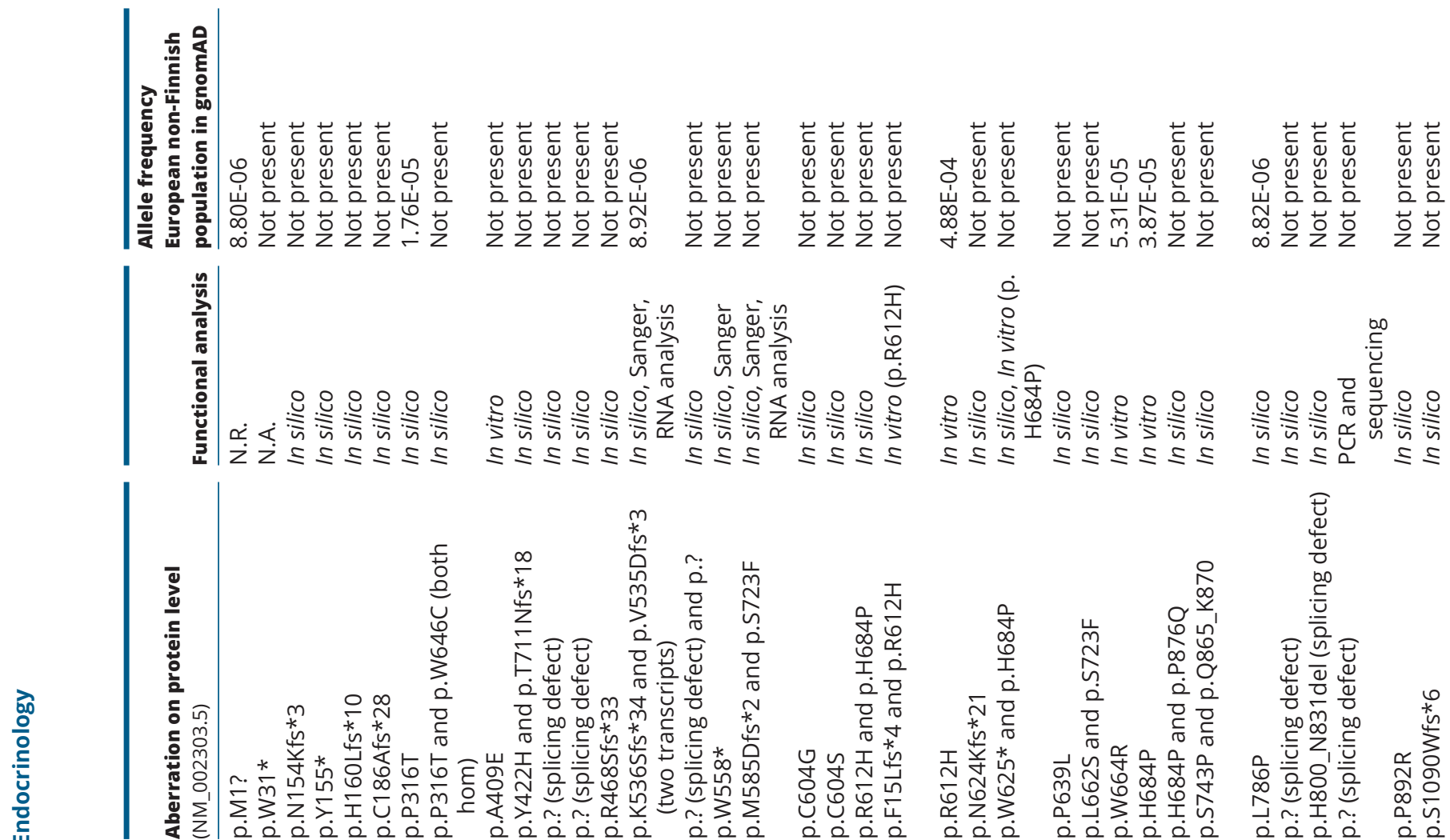

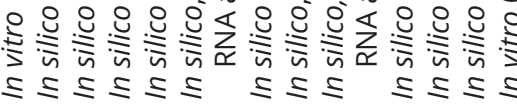

$\leq \leq \leq \leq \leq \leq \leq \leq$

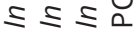

$\leqslant \leqq$

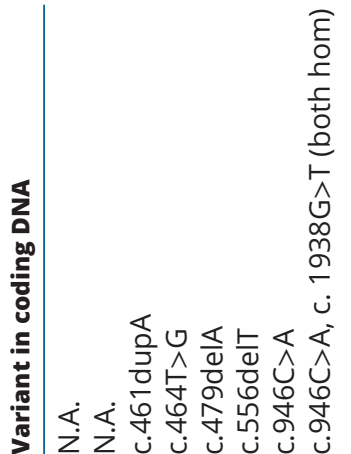

으으응
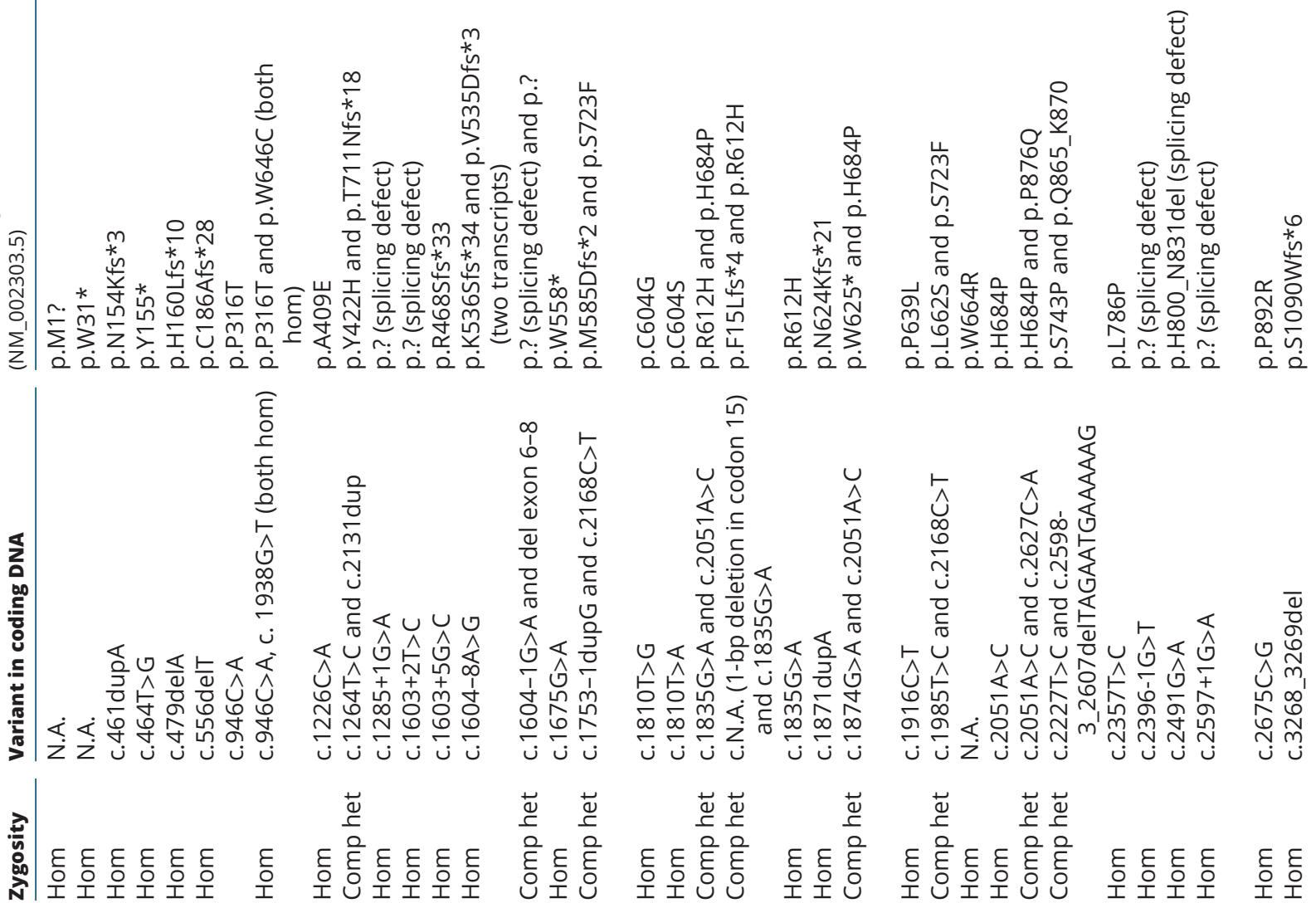

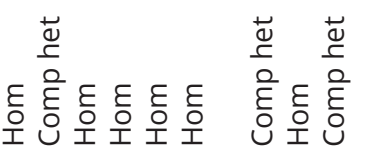

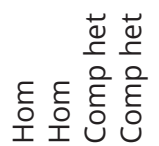

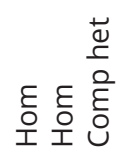

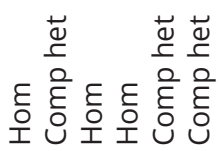

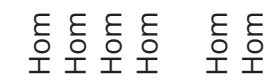

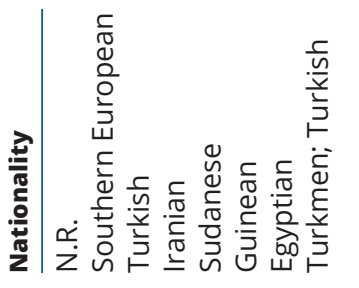

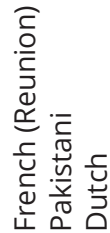

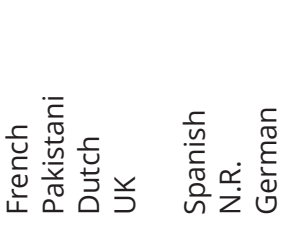

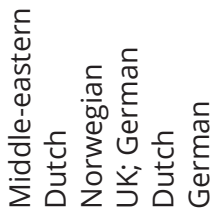

$\stackrel{\mathscr{\nu}}{\mathscr{N}}$

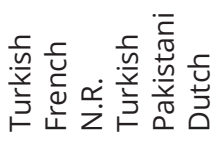

$-N-$

$-N-r$

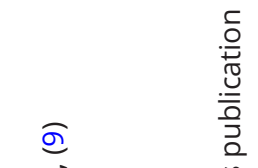

产

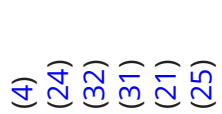

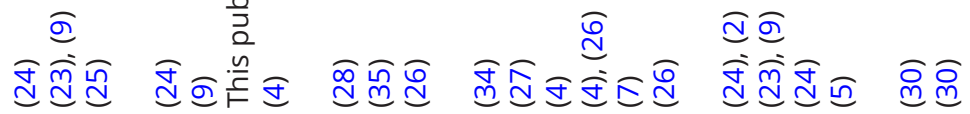

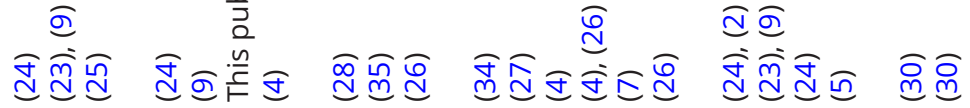




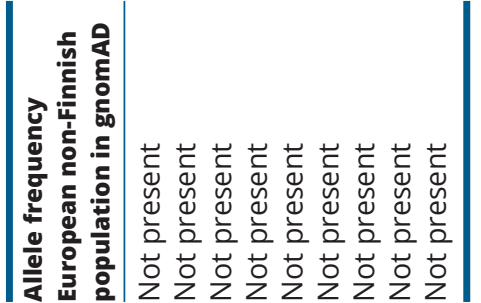

are from high-income countries with well-established diagnostic genetic facilities. Another explanation why patients with LepR deficiency are not identified, is that the clinical phenotype is not sufficiently recognized. Our systematic literature search shows that the majority of patients do not have pituitary hormonal disturbances. It is hypothesized that there might be a genotype-phenotype correlation reflecting residual leptin receptor function in those cases (3), but the amount of patients is too small to draw conclusions. Thus, LepR deficiency should be suspected in all cases of severe early-onset obesity and hyperphagia, even without signs of hypopituitarism, especially in the case of consanguinity. In the most common monogenic obesity disorder, $M C 4 R$ deficiency, segregation studies have shown incomplete expressivity and penetrance for the obesity phenotype (38). However, this is not likely for LepR deficiency, as there are no individuals present with biallelic pathogenic $L E P R$ variants in gnomAD nor in large control cohorts without obesity $(6,39)$.

A more daunting possible cause of the discrepancy between amount of described patients versus predicted patients is mortality. Young age of known patients and absence of adult LepR deficiency patients in several large adult cohorts with early-onset obesity $(6,7,8)$ could suggest that these patients decease before they are identified. This may occur due to the consequences of their severe obesity, but mortality in early childhood due to infections has also been reported $(4,29)$. Long-term follow-up studies of the clinical course of LepR deficiency have however not yet been performed. These studies are also needed because in some cases, improvement of the endocrine phenotype after puberty has been reported (Supplementary Table 1), however, without a clear explanation. Le Beyec et al. reported resolving of central hypothyroidism from age 16 years onward and hypogonadism from age 19 years onward in a male patient (20). Dehghani et al. reported that two affected males in a consanguineous family showed BMI normalization from puberty onset onward, in contrast to the affected females in this family who did not show improvement of BMI nor hypogonadotropic hypogonadism, suggesting a sex-specific effect might be present (29). However, Nizard et al. reported resolving of hypogonadotropic hypogonadism in a female patient from age 18 years onward and occurrence of natural pregnancy 2 years after gastric bypass surgery (40), which challenges the assumption that hormonal disturbances only resolve in male patients. However, the number of patients is too low to draw conclusions on this phenomenon. 


\section{Strengths and limitations}

To the best of our knowledge, this is the first systematic literature overview of LepR deficiency cases. We identified 86 published cases, compared to the 57 cases in a previous, non-systematic overview from 2018 (3). A strength of this study is that we could add clinical information from $26 / 86$ (30\%) known LepR deficiency cases by contacting authors. Another strength is our stringent variant selection. There is always an insecurity regarding the pathogenicity of variants when functional tests have not been performed. This is even the case for variants identified in patients with clear LepR deficiency phenotypes, such as the male patient described earlier. In 2018, Ayers et al. presented a prevalence calculation for LepR deficiency in the United States (41). However, they estimated prevalence using a far less stringent method by adding variants predicted to be pathogenic solely on the basis of in silico prediction tools. It is known that these tools are not specific, leading to high false-positive rates (42). When we would use their method, this would lead to a prevalence estimation of 8953 patients (95\% CI: 7880-10 027 patients). This would be a significant overestimation, whereas our calculation would rather yield an underestimation of actual number of patients. An important limitation of our study is that only $7 / 45$ distinct pathogenic variants identified in patients with LepR deficiency were present in the European gnomAD population. Therefore, when sample size of sequencing data in population databases expands, prevalence calculations might yield a higher number of patients. Another limitation of our calculation is that first-degree relatives from patients with severe pediatric diseases, such as LepR deficiency, are removed from gnomAD, which could have led to a lower allele frequency of pathogenic LEPR variants. Moreover, we are aware that it is possible that some diagnosed patients have not been described in literature yet. This could lead to a higher prevalence calculation if these patients have novel LEPR variants. Thus, our current prevalence calculation should be seen as a minimum estimation.

\section{Conclusion}

LepR deficiency is an endocrine obesity disorder for which encouraging treatment options recently became available. Genetic testing in patients with early-onset obesity, hyperphagia, and/or LepR-associated hormone disturbances is therefore more important than ever. By using large population-based genetic data, we estimated the prevalence of this rare disease in Europe. Our data suggest that the majority of patients with LepR deficiency in Europe are currently not recognized. Improving awareness and availability of genetic testing for earlyonset obesity is needed to help these patients gain access to newly developed effective treatment.

\section{Supplementary materials}

This is linked to the online version of the paper at https://doi.org/10.1530/ EJE-19-0678.

\section{Declaration of interest}

The authors declare that there is no conflict of interest that could be perceived as prejudicing the impartiality of this study.

\section{Funding}

O A was supported by the Elisabeth Foundation, a non-profit foundation supporting academic obesity research.

\section{Acknowledgements}

The authors thank the (corresponding) authors of papers describing patients with LepR deficiency who provided additional patient details: Prof. I Mazen, Prof. W K Chung, Prof. T Hansen, Prof. M Arslan, Prof. P Froguel, Prof. R Jockers, Dr A Bişgin, Dr R K Niazi, Dr J Dam, Dr N Mirza, Dr R Rodríguez López, and R Melero Valverde. The authors thank U Özaydın, computer scientist, and K Mauff, statistician, for their help with the prevalence calculation and E Krabbendam, biomedical information specialist, for her help with the systematic literature search.

\section{References}

1 GBD 2015 Obesity Collaborators, Afshin A, Forouzanfar MH, Reitsma MB, Sur P, Estep K, Lee A, Marczak L, Mokdad AH, MoradiLakeh $\mathrm{M}$ et al. Health effects of overweight and obesity in 195 countries over 25 years. New England Journal of Medicine 2017377 13-27. (https://doi.org/10.1056/NEJMoa1614362)

2 Clement K, Biebermann H, Farooqi IS, Van der Ploeg L, Wolters B, Poitou C, Puder L, Fiedorek F, Gottesdiener K, Kleinau G et al. MC4R agonism promotes durable weight loss in patients with leptin receptor deficiency. Nature Medicine 201824 551-555. (https://doi. org/10.1038/s41591-018-0015-9)

3 Nunziata A, Funcke JB, Borck G, von Schnurbein J, Brandt S, Lennerz B, Moepps B, Gierschik P, Fischer-Posovszky P \& Wabisch M. Functional and phenotypic characteristics of human leptin receptor mutations. Journal of the Endocrine Society 20193 27-41. (https://doi. org/10.1210/js.2018-00123)

4 Farooqi IS, Wangensteen T, Collins S, Kimber W, Matarese G, Keogh JM, Lank E, Bottomley B, Lopez-Fernandez J, Ferraz-Amaro I et al. Clinical and molecular genetic spectrum of congenital deficiency of the leptin receptor. New England Journal of Medicine 2007356 237-247. (https://doi.org/10.1056/NEJMoa063988)

5 Clément K, Vaisse C, Lahlou N, Cabrol S, Pelloux V, Cassuto D, Gourmelen M, Dina C, Chambaz J, Lacorte JM et al. A mutation in the human leptin receptor gene causes obesity and pituitary dysfunction. Nature 1998392 398-401. (https://doi. org/10.1038/32911)

6 Nordang GBN, Busk OL, Tveten K, Hanevik HI, Fell AKM, Hjelmesaeth J, Holla $\mathrm{O} \&$ Hertel J. Next-generation sequencing of the monogenic obesity genes LEP, LEPR, MC4R, PCSK1 and POMC 
in a Norwegian cohort of patients with morbid obesity and normal weight controls. Molecular Genetics and Metabolism 2017121 51-56. (https://doi.org/10.1016/j.ymgme.2017.03.007)

7 Kleinendorst L, Massink MPG, Cooiman MI, Savas M, van der Baan-Slootweg OH, Roelants RJ, Janssen ICM, Meijers-Heijboer HJ, Knoers NVAM, Ploos van Amstel HK et al. Genetic obesity: nextgeneration sequencing results of 1230 patients with obesity. Journal of Medical Genetics 201855 578-586. (https://doi.org/10.1136/ jmedgenet-2018-105315)

8 Hendricks AE, Bochukova EG, Marenne G, Keogh JM, Atanassova N, Bounds R, Wheeler E, Mistry V, Henning E, Korner A et al. Rare variant analysis of human and rodent obesity genes in individuals with severe childhood obesity. Scientific Reports 20177 4394. (https:// doi.org/10.1038/s41598-017-03054-8)

9 Saeed S, Bonnefond A, Manzoor J, Shabir F, Ayesha H, Philippe J, Durand E, Crouch H, Sand O, Ali M et al. et al. Genetic variants in LEP, LEPR, and MC4R explain 30\% of severe obesity in children from a consanguineous population. Obesity 201523 1687-1695. (https:// doi.org/10.1002/oby.21142)

10 Firth HV, Richards SM, Bevan AP, Clayton S, Corpas M, Rajan D, Van Vooren S, Moreau Y, Pettett RM \& Carter NP. DECIPHER: Database of Chromosomal Imbalance and Phenotype in Humans using Ensembl resources. American Journal of Human Genetics 200984 524-533. (https://doi.org/10.1016/j.ajhg.2009.03.010)

11 Landrum MJ, Lee JM, Benson M, Brown GR, Chao C, Chitipiralla S, Gu B, Hart J, Hoffman D, Jang W et al. ClinVar: improving access to variant interpretations and supporting evidence. Nucleic Acids Research 201846 D1062-D1067. (https://doi.org/10.1093/nar/ gkx1153)

12 Stenson PD, Ball EV, Mort M, Phillips AD, Shiel JA, Thomas NS, Abeysinghe S, Krawczak M \& Cooper DN. Human Gene Mutation Database (HGMD): 2003 update. Human Mutation 200321 577-581. (https://doi.org/10.1002/humu.10212)

13 World Health Organization. WHO child growth standards: length/ height-for-age, weight-for-age, weight-for-length, weight-for-height and body mass index-for-age: methods and development. World Health Organization, 2006. (available at: https://www.who.int/ childgrowth/standards/en/). Accessed on 31 May 2019.

14 Schönbeck Y, Talma H, van Dommelen P, Bakker B, Buitendijk SE, Hirasing RA \& van Buuren S. Increase in prevalence of overweight in Dutch children and adolescents: a comparison of nationwide growth studies in 1980, 1997 and 2009. PLOS ONE 20116 e27608. (https:// doi.org/10.1371/journal.pone.0027608)

15 Richards S, Aziz N, Bale S, Bick D, Das S, Gastier-Foster J, Grody WW, Hegde M, Lyon E, Spector E et al. Standards and guidelines for the interpretation of sequence variants: a joint consensus recommendation of the American College of Medical Genetics and Genomics and the Association for Molecular Pathology. Genetics in Medicine 201517 405-424. (https://doi.org/10.1038/gim.2015.30)

16 Chakraborty R, Srinivasan MR \& Daiger SP. Evaluation of standard error and confidence interval of estimated multilocus genotype probabilities, and their implications in DNA forensics. American Journal of Human Genetics 199352 60-70.

17 Mazen I, El-Gammal M, Abdel-Hamid M, Farooqi IS \& Amr K. Homozygosity for a novel missense mutation in the leptin receptor gene (P316T) in two Egyptian cousins with severe early onset obesity. Molecular Genetics and Metabolism 2011102 461-464. (https://doi. org/10.1016/j.ymgme.2010.12.013)

18 Andiran N, Çelik N \& Andiran F. Homozygosity for two missense mutations in the leptin receptor gene (P316T;W646C) in a Turkmenian girl with severe early-onset obesity. Journal of Pediatric Endocrinology and Metabolism 201124 1043-1045. (https://doi. org/10.1515/JPEM.2011.313)

19 Vauthier V, Jaillard S, Journel H, Dubourg C, Jockers R \& Dam J. Homozygous deletion of an 80kb region comprising part of DNAJC6 and LEPR genes on chromosome 1 P31.3 is associated with early onset obesity, mental retardation and epilepsy. Molecular Genetics and Metabolism 2012106 345-350. (https://doi.org/10.1016/j. ymgme.2012.04.026)

20 Le Beyec J, Cugnet-Anceau C, Pépin D, Alili R, Cotillard A, Lacorte JM, Basdevant A, Laville M \& Clément K. Homozygous leptin receptor mutation due to uniparental disomy of chromosome 1: response to bariatric surgery. Journal of Clinical Endocrinology and Metabolism 2013 98 E397-E402. (https://doi.org/10.1210/jc.2012-2779)

21 Kakar N, Ahmad J, Kubisch C \& Borck G. Exon skipping and severe childhood-onset obesity caused by a leptin receptor mutation. American Journal of Medical Genetics: Part A 2013 161A 2672-2674. (https://doi.org/10.1002/ajmg.a.36125)

22 Gill R, Cheung YH, Shen Y, Lanzano P, Mirza NM, Ten S, MacLaren NK, Motaghedi R, Han JC, Yanovski JA et al. Whole-exome sequencing identifies novel LEPR mutations in individuals with severe early onset obesity. Obesity 201422 576-584. (https://doi. org/10.1002/oby.20492)

23 Saeed S, Bonnefond A, Manzoor J, Philippe J, Durand E, Arshad M, Sand O, Butt TA, Falchi M, Arslan M et al. Novel LEPR mutations in obese Pakistani children identified by PCR-based enrichment and next generation sequencing. Obesity 201422 1112-1117. (https:// doi.org/10.1002/oby.20667)

24 Huvenne H, Le Beyec J, Pepin D, Alili R, Kherchiche PP, Jeannic E, Frelut M, Lacorte J, Nicolino M, Viard A et al. Seven novel deleterious LEPR mutations found in early-onset obesity: a DELTAExon6-8 shared by subjects from Reunion Island, France, suggests a founder effect. Journal of Clinical Endocrinology and Metabolism 2015100 E757-166. (https://doi.org/10.1210/jc.2015-1036)

25 Hannema SE, Wit JM, Houdijk ME, Van Haeringen A, Bik EC, Verkerk AJMH, Uitterlinden AG, Kant SG, Oostdijk W, Bakker E et al. Novel leptin receptor mutations identified in two girls with severe obesity are associated with increased bone mineral density. Hormone Research in Paediatrics 201685 412-420. (https://doi. org/10.1159/000444055)

26 Kohlsdorf K, Nunziata A, Funcke JB, Brandt S, von Schnurbein J, Vollback H, Lennerz B, Fritsch M, Greber-Platzer S, FröhlichReiterer E et al. Early childhood BMI trajectories in monogenic obesity due to leptin, leptin receptor, and melanocortin 4 receptor deficiency. International Journal of Obesity 201842 1602-1609. (https://doi.org/10.1038/s41366-018-0049-6)

27 Kleinendorst L, Van Haelst MM \& Van Den Akker ELT. Young girl with severe early-onset obesity and hyperphagia. BMJ Case Reports 2017 2017 bcr-2017-221067. (https://doi.org/10.1136/bcr-2017-221067)

28 Albuquerque D, Estévez MN, Víbora PB, Giralt PS, Balsera AM, Cortés PG, López MJ, Luego LM, Gervasini G, Hernández SB et al. Novel variants in the MC4R and LEPR genes among severely obese children from the Iberian population. Annals of Human Genetics 2014 78 195-207. (https://doi.org/10.1111/ahg.12058)

29 Dehghani MR, Mehrjardi MYV, Dilaver N, Tajamolian M, Enayati S, Ebrahimi P, Amoli MM, Farooqi S \& Maroofian R. Potential role of gender specific effect of leptin receptor deficiency in an extended consanguineous family with severe early-onset obesity. European Journal of Medical Genetics 201861 465-467. (https://doi org/10.1016/j.ejmg.2018.03.006)

30 Niazi RK, Gjesing AP, Hollensted M, Have CT, Grarup N, Pedersen O, Ullah A, Shahid G, Ahmad W, Gul A et al. Identification of novel LEPR mutations in Pakistani families with morbid childhood obesity. BMC Medical Genetics 201819 199. (https://doi.org/10.1186/s12881018-0710-x)

31 Armagan C, Yilmaz C, Koc A, Abaci A, Ulgenalp A, Bober E, Ercal D \& Demir K. A toddler with a novel LEPR mutation. Hormones 201918 237-240. (https://doi.org/10.1007/s42000-019-00097-6)

32 Algariri N, Alhabib M \& Alsaheel A. A novel mutation leading to leptin receptor deficiency and subsequent childhood morbid obesity. Journal of Endocrinology and Diabetes 20174 1-2. (https://doi. org/10.15226/2374-6890/4/4/00187) 
33 Bhatt A, Purani C, Bhargava P, Patel K, Agarbattiwala T, Puvar A, Shah K, Joshi CG, Dhamecha N, Prabhakar M et al. Whole exome sequencing reveals novel LEPR frameshift mutation in severely obese children from Western India. Molecular Genetics and Genomic Medicine 20197 e00692. (https://doi.org/10.1002/mgg3.692)

34 Bisgin A. LEPR deficiency: prevalence and importance of a novel mutation and significant genetic variants, usually underestimated. Turkish Journal of Endocrinology and Metabolism 201822 85-90. (https://doi.org/10.25179/tjem.2018-59842)

35 Le Beyec-Le Bihan J, Poitou-Bernert C, Karsenty A, Pelloux V, Lacorte JM, Tounian P, Oppert JM, Clement K \& Dubern B. Variants in genes of the leptin/melanocortin pathway are involved in 3\% of cases of early-onset severe obesity. Endocrine Abstracts 201963 GP132. (https://doi.org/10.1530/endoabs.63.GP132)

36 Styne DM, Arslanian SA, Connor EL, Farooqi IS, Murad MH, Silverstein JH \& Yanovski JA. Pediatric obesity-assessment, treatment, and prevention: an Endocrine Society clinical practice guideline. Journal of Clinical Endocrinology and Metabolism 2017102 709-757. (https://doi.org/10.1210/jc.2016-2573)

37 Dayton K \& Miller J. Finding treatable genetic obesity: strategies for success. Current Opinion in Pediatrics 201830 526-531. (https://doi. org/10.1097/MOP.0000000000000641)
38 Dubern B, Clement K, Pelloux V, Froguel P, Girardet JP, Guy-Grand B $\&$ Tounian P. Mutational analysis of melanocortin-4 receptor, agoutirelated protein, and alpha-melanocyte-stimulating hormone genes in severely obese children. Journal of Pediatrics 2001139 204-209. (https://doi.org/10.1067/mpd.2001.116284)

39 Serra-Juhe C, Martos-Moreno GÁ, Bou de Pieri F, Flores R, Chowen JA, Perez-Jurado LA \& Argente J. Heterozygous rare genetic variants in non-syndromic early-onset obesity. International Journal of Obesity 2019. (https://doi.org/10.1038/s41366-019-0357-5)

40 Nizard J, Dommergue M \& Clément K. Pregnancy in a woman with a leptin-receptor mutation. New England Journal of Medicine 2012366 1064-1065. (https://doi.org/10.1056/NEJMc1200116)

41 Ayers KL, Glicksberg BS, Garfield AS, Longerich S, White JA, Yang P, Du L, Chittenden TW, Gulcher JR, Roy S et al. Melanocortin 4 receptor pathway dysfunction in obesity: patient stratification aimed at MC4R agonist treatment. Journal of Clinical Endocrinology and Metabolism 2018103 2601-2612. (https://doi.org/10.1210/jc.201800258)

42 Flanagan SE, Patch AM \& Ellard S. Using SIFT and PolyPhen to predict loss-of-function and gain-of-function mutations. Genetic Testing and Molecular Biomarkers 201014 533-537. (https://doi. org/10.1089/gtmb.2010.0036)

Received 23 August 2019

Revised version received 14 October 2019

Accepted 22 October 2019 